\title{
Determination of Oxygen in High-purity Zinc, Bismuth, Lead, Antimony and Copper by the Vacuum Fusion Method
}

\author{
By Morimasa Saito* and Emiko Sudo*†
}

\begin{abstract}
The determination of micro-amounts of oxygen in high-purity zinc, bismuth, lead, antimony and copper by the vacuum fusion method was performed.

For the determination of oxygen in zinc, bismuth, lead, antimony, a carbon chip-tin nickel foil bath was used. After the sample was dropped into a crucible at a temperature between 973 and $1323 \mathrm{~K}$, the crucible temperature was raised to $1173-1323 \mathrm{~K}$ at the rate of $373 \mathrm{~K} / 60 \mathrm{~s}$ and gases were extracted for $300 \mathrm{~s}$. For the determination of oxygen in copper, the carbon chip method was applied at $1723 \mathrm{~K}$. The recovery of oxygen in these metal oxides by this method was $95-100 \%$.
\end{abstract}

(Received August 9, 1986)

Keywords: vacuum fusion method, oxygen, zinc, bismuth, lead, antimony, copper, carbon chip-tin-nickel foil bath

\section{Introduction}

Physical and mechanical properties of zinc, bismuth, lead, antimony and copper are markedly influenced by oxygen included in them. To clarify these effects, an accurate and sensitive analytical method for determination of oxygen in those metals is required.

For the determination of oxygen in zinc, bismuth, lead and antimony the hydrogen sulfide method and the sulfur vapor one have been reported ${ }^{(1)(2)}$, but these methods required very large samples and a high toric gas. The hydrogen-reduction method ${ }^{(3)-(7)}$ has been also applied to the determination of oxygen in zinc, bismuth, lead and copper. This method is sensitive but poor in precision. The activation analysis which is not a conventional technique is used to determine oxygen in powder zinc ${ }^{(8)}$, lead and bismuth ${ }^{(9)}$. The carrier gas method using solid carbon or naphtalene as reaction reagents ${ }^{(10)(11)}$ is also used, and this technique has the great advantage for the determination of oxygen in metal compounds.

* National Research Institute for Metals, Meguro-ku, Tokyo 153, Japan.

† Present address: Toho Kaken Co., Koshigaya-shi, Saitama.
Oxygen in metals is usually determined by the vacuum fusion method and the inert gas fusion one. It is said that these methods are difficult for the determination of oxygen in zinc, bismuth, lead and antimony having high vapor pressure except copper because of socalled "gettering effect" of these metals at high temperature. Griffith et al. ${ }^{(12)}$ reported on the successfull use of a carbon-bath operating at $1023 \mathrm{~K}$ for the determination of oxygen in antimony. Yoneda ${ }^{(13)}$ described the method for determination of oxygen in bismuth, lead and antimony by the inert gas fusion method using graphite boats operating at temperatures from 973 to $1073 \mathrm{~K}$, but this method required a large amount of samples $(20 \mathrm{~g})$ and gave poor precision.

The method using a carbon chip and tinnickel foil bath, which had been developed for the determination of oxygen in volatile metals such as aluminum, manganese ${ }^{(14)}$ and beryllium $^{(15)}$, was proposed and applied to the determination of oxygen content in zinc, bismuth, lead and antimony.

For the determination of oxygen in copper the vacuum fusion and inert gas fusion methods have been developed ${ }^{(16)}$. However, as the oxygen content in oxygen-free copper is less than $5 \mathrm{ppm}$, the determination of ultramicro amounts of oxygen has been required. 
To determine less than $5 \mathrm{ppm}$ of oxygen by the above-mentioned method, more than $3 \mathrm{~g}$ of sample were necessary because of the sensitivities of the method and of the influence of blank values from the graphite crucible. But the use of a large amount of the sample often gave inaccurate results and incomplete extraction. In order to overcome these difficulties, the method using a carbon chip ${ }^{(17)}$ was applied to the determination of ultra-micro amounts of oxygen in copper.

\section{Experimental}

\section{Apparatus and materials}

The apparatus used in this study was a Rigo Company's analyzer for gases in metals of SHO-II type (sensitivity: $0.0055 \mathrm{mg} / \mathrm{mmOil}$ ). The graphite crucible (OT2400) manufactured by Owada Carbon Co. was $200 \mathrm{~mm}$ in diameter and $70 \mathrm{~mm}$ in depth, and the graphite powder (P2400) used was in the range of $-0.0074 \mathrm{~mm}$ in size. A graphite lid was used in order to diminish the adsorption of metals on the wall of the furnace. The temperature of the crucible was measured with an optical pyrometer and a 2-color eye.

Materials used as a bath include a high-purity nickel foil (Oxygen: $30 \mathrm{ppm}$ ) about $50 \mu$ in thickness, electric tin and carbon chip(0.84-1 $\mathrm{mm}$ ) made from a graphite crucible by a hammer. Samples to be analyzed were pure zinc, bismuth, lead and antimony manufactured by Johnson Matthey Chemicals Co. and commercial copper and oxygen-free copper. The block samples were prepared by cutting to $1-3 \mathrm{~g}$ in size with a hacksaw and abrading the surface with a fine file, then rinsed in petroleum benzene, methyl alcohol, allowed to dry with a hot blower and weighed. Next each sample was wrapped with a nickel foil which was 0.4-1 times as weigh as the sample. Each of the powder samples was also wrapped with a nickel foil.

\section{Procedure}

The procedure in the case of zinc, bismuth, lead and antimony was as follows. Carbon chip $(0.84-1 \mathrm{~mm})$ weighing $4 \mathrm{~g}$ were previously placed in the crucible and degassed at about $2273 \mathrm{~K}$. When the blank values of oxygen became low and constant, the crucible temperature was reduced to $1673 \mathrm{~K}$, and both nickel $(0.3 \mathrm{~g})$ and $\operatorname{tin}(0.1 \mathrm{~g})$ were dropped into the crucible. After degassing, the crucible temperature was reduced to $1273 \mathrm{~K}$, and then tin of $0.1 \mathrm{~g}$ was added to the bath. The crucible temperature was raised to $1573 \mathrm{~K}$ and then reduced to the temperature of sample dropping. The temperatures for dropping of zinc, bismuth, lead and antimony were $973 \mathrm{~K}, 1023 \mathrm{~K}, 973 \mathrm{~K}$ and $1023 \mathrm{~K}$, respectively. The temperature of the crucible was raised to the final gas extraction temperature at the rate of $373 \mathrm{~K} / 60 \mathrm{~s}$, and gases were extracted for $120-300 \mathrm{~s}$. The final gas extraction temperature for zinc, bismuth, lead and antimony were 1373, 1323, 1273 and $1123 \mathrm{~K}$, respectively. Before the next sample was dropped into the crucible, carbon chip of $0.4 \mathrm{~g}$ were added and the above-mentioned procedure was repeated. The analytical procedure for copper was as follow. Carbon chip weighing $4 \mathrm{~g}$ were previously placed in the crucible and degassed at $2573 \mathrm{~K}$. When the blank values of oxygen became low, the crucible temperature was reduced to $1773 \mathrm{~K}$ and the sample (without nickel foil) was dropped into the crucible and gases were extracted for about $600 \mathrm{~s}$. Before the next sample was dropped into the crucible, carbon chip of $0.4 \mathrm{~g}$ were added.

\section{Results and Discussion}

\section{Gas extraction curves and temperature}

The gas extraction curves for zinc or for only $\mathrm{ZnO}$ (Johnson Matthey Chem.) were examined. After carbon chip were added to the crucible together with tin $(0.1 \mathrm{~g})$, zinc of $0.3 \mathrm{~g}$ or $\mathrm{ZnO}$ of $3 \mathrm{mg}$ wrapped with a nickel foil $(0.15 \mathrm{~g})$ was dropped into the crucible at $973 \mathrm{~K}$ and then the crucible temperature was raised to $1573 \mathrm{~K}$ at the rate of about $373 \mathrm{~K} / 60 \mathrm{~s}$. The accuracy for the measurement of the crucible temperature was within $\pm 10 \mathrm{~K}$. Figure 1 shows typical gas extraction curves for zinc and $\mathrm{ZnO}$. This method was predicted to separate hydrogen, nitrogen and oxygen, and especially to discriminate among the forms of oxide con- 


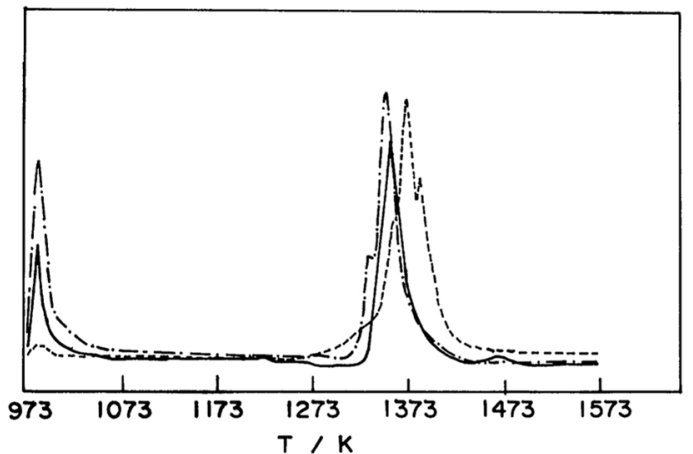

Fig. 1 Gas extraction curves for zinc at various operating temperatures: (-) Zn (oxygen: 0.17\%); (--) Zn (oxygen: $0.010 \%)$; (-- $) \mathrm{ZnO}(30 \mathrm{mg})$.

tained in metals, as described in previous papers $^{(14)(15)(17)}$. The first peak at $1023 \mathrm{~K}$ was due to hydrogen in zinc, and as the peak at 1223$1373 \mathrm{~K}$ coincided with that of $\mathrm{ZnO}$, it seems to be due to $\mathrm{ZnO}$ contained in zinc samples. In addition, as Fig. 1 shows, the final gas extraction was sufficiently made at $1373 \mathrm{~K}$.

The oxygen extraction temperature was next examined. Table 1 shows the results obtained by using the samples $\mathrm{Zn}-1, \mathrm{Zn}-2$ and $\mathrm{ZnO}$. When the samples were extracted at 1673,1473 and $1273 \mathrm{~K}$, the oxygen recovery for $\mathrm{ZnO}$ was under $95 \%$ and the oxygen extraction was lower. Thus, when the sample was dropped into the crucible at $973 \mathrm{~K}$ and the crucible temperature was raised to $1373 \mathrm{~K}$ at the rate of $373 \mathrm{~K} / 60 \mathrm{~s}$ and gases were extracted for $120 \mathrm{~s}$, the oxygen extraction from the samples was higher and the recovery for $\mathrm{ZnO}$ was $100 \%$. Therefore, this procedure was applied to the determination of oxygen amount not only in zinc, but also in bismuth, lead and antimony.
The gas extraction curves for bismuth or $\mathrm{Bi}_{2} \mathrm{O}_{3}$ were examined. Figure 2 shows the results. Oxygen in the bismuth sample and $\mathrm{Bi}_{2} \mathrm{O}_{3}$ was extracted at temperatures of below $1323 \mathrm{~K}$. Thus, the final gas extraction temperature for the bismuth samples was $1323 \mathrm{~K}$, and the duration $300 \mathrm{~s}$ was sufficient at this temperature.

As Fig. 2 shows, in the block bismuth sample, only the peak at $1313 \mathrm{~K}$ was shown, but in $\mathrm{Bi}_{2} \mathrm{O}_{3}$, there were peaks at several temperatures. This result shows that $\mathrm{Bi}_{2} \mathrm{O}_{3}$ was allowed to react complexly with carbon, but details of this reaction are not evident. Further investigations are necessary to clarify this matter.

Figure 3 shows typical gas extraction curves for the lead samples. Oxygen for both the block lead samples and $\mathrm{PbO}$ was completely extracted at $1143 \mathrm{~K}$. In the lead samples the gettering effect of lead was greatly increased,

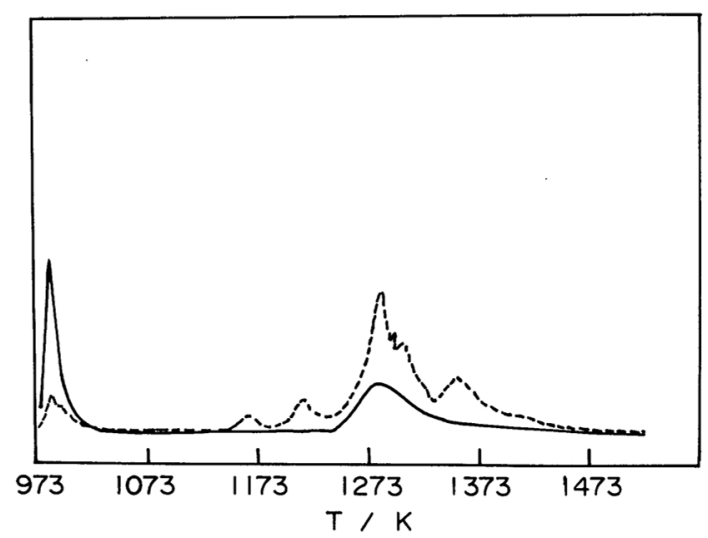

Fig. 2 Gas extraction curves for bismuth at various operating temperatures: (-) $\mathrm{Bi}$ (block, oxygen: $0.0037 \%$ ); (-- ) $\mathrm{Bi}_{2} \mathrm{O}_{3}$ (34 mg).

Table 1 Relation between oxygen values in zinc and gas extraction temperature.

\begin{tabular}{|c|c|c|c|c|}
\hline \multirow[b]{2}{*}{ Sample } & \multicolumn{3}{|c|}{ Extraction temperature $(\mathbf{K})$} & \multirow[b]{2}{*}{$\begin{array}{l}973 \rightarrow 1373 \\
\text { Found }(\%)\end{array}$} \\
\hline & $\begin{array}{c}1673 \\
\text { Found(\%) }\end{array}$ & $\begin{array}{c}1473 \\
\text { Found }(\%)\end{array}$ & $\begin{array}{c}1273 \\
\text { Found }(\%)\end{array}$ & \\
\hline \multirow[t]{2}{*}{ Zn-1 } & 0.0002 & 0.0004 & 0.0007 & 0.0008 \\
\hline & 0.0004 & 0.0003 & 0.0005 & 0.0009 \\
\hline \multirow[t]{2}{*}{$\mathrm{Zn}-2$} & 0.14 & 0.15 & 0.18 & 0.18 \\
\hline & 0.13 & 0.17 & 0.17 & 0.18 \\
\hline \multirow[t]{2}{*}{$\mathrm{ZnO}^{*}$} & $65 * *$ & $90 * *$ & $96 * *$ & $99^{* *}$ \\
\hline & $70^{* *}$ & $95^{* *}$ & $94^{* *}$ & $102^{* *}$ \\
\hline
\end{tabular}

* $\mathrm{ZnO}$ taken: $10 \mathrm{mg}$. ** Oxygen recovery(\%). 


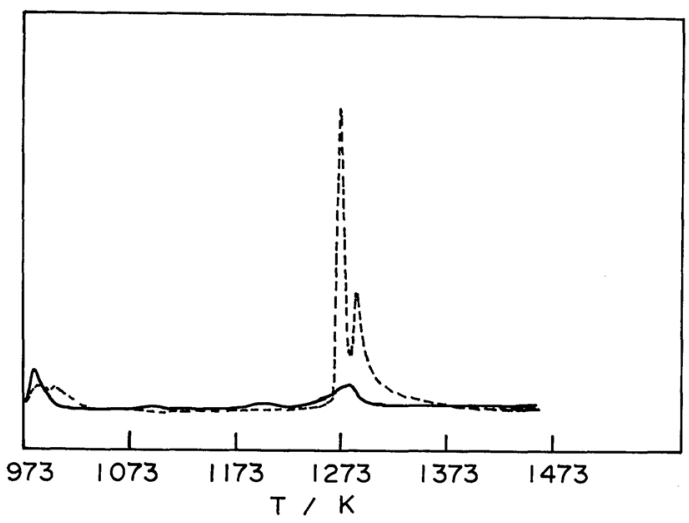

Fig. 3 Gas extraction curves for lead at various operating temperatures: ( $-\mathrm{Pb}$ (block, oxygen: 0.0075\%); (-- ) $\mathrm{PbO}(34 \mathrm{mg})$.

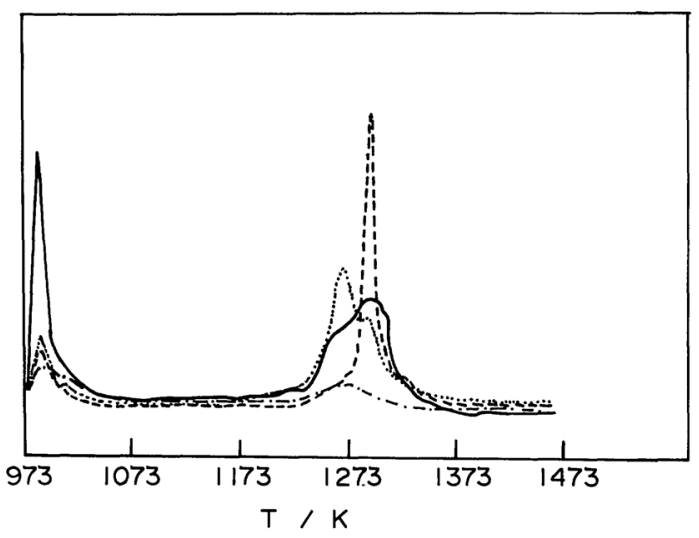

Fig. 4 Gas extraction curves for antimony at various operating temperatures: $(-\mathrm{Sb}$ (powder, oxygen: $0.22 \%$ ); (-,-) Sb (block, oxygen: 0.0093\%); (-- ) $\mathrm{Sb}_{2} \mathrm{O}_{3}(20 \mathrm{mg}) ;(\cdots) \mathrm{Sb}_{2} \mathrm{O}_{4}(22 \mathrm{mg})$.

when the crucible temperature was raised up to $1273 \mathrm{~K}$. Thus, the final gas extraction was carried out below $1273 \mathrm{~K}$ for $300 \mathrm{~s}$.

Figure 4 shows typical gas extraction curves of antimony. Peaks were present at 1223-1323 $\mathrm{K}$. In the block antimony sample, a peak was shown at $1223-1273 \mathrm{~K}$. This seems to be due to $\mathrm{Sb}_{2} \mathrm{O}_{3}$ contained in samples because of the coincidence with the peak of $\mathrm{Sb}_{2} \mathrm{O}_{3}$. However, in the powder antimony, th broad peak was shown at $1223-1323 \mathrm{~K}$. The peak for only $\mathrm{Sb}_{2} \mathrm{O}_{4}$ appeared at about $1233 \mathrm{~K}$. From this fact, this broad peak seems to be due to both $\mathrm{Sb}_{2} \mathrm{O}_{3}$ and $\mathrm{Sb}_{2} \mathrm{O}_{4}$ contained in the powder sample. Also, as Fig. 4 shows, the final gas extrac-

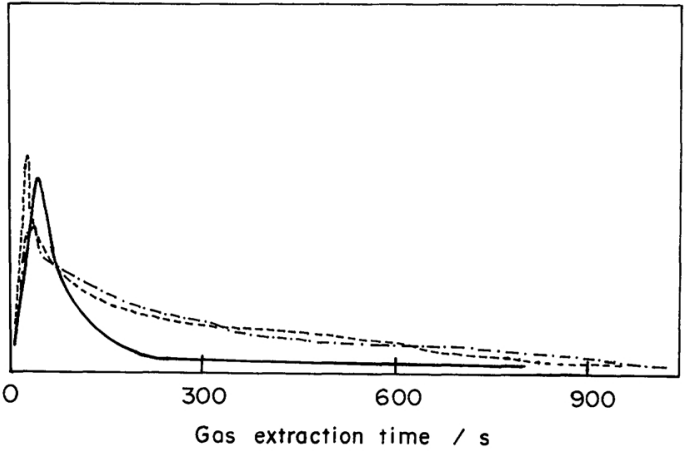

Fig. 5 Gas extraction curves for copper: (-) Carbon chip method; (--) No bath; (-- ) Fe bath method.

tion temperature was $1323 \mathrm{~K}$, since oxygen in the samples was completely extracted at this temperature.

Figure 5 shows typical gas extraction curves in copper at $1773 \mathrm{~K}$. When the copper samples were heated at temperatures higher than 1873 $\mathrm{K}$, the oxygen extraction time slightly decreased, but the gettering of copper on the furnace wall increased. Therefore, the optimum oxygen extraction temperature was $1773 \mathrm{~K}$. However, when oxygen in copper was determined by the conventional dry crucible (no bath) method or the iron-bath one, the gentle extraction curve of gases was found as shown in Fig. 5. And it was very difficult for us to judge the final gases extraction point. In addition, when copper samples more than $3 \mathrm{~g}$ were used, the time necessary for extraction of oxygen was more than $1.2 \mathrm{ks}$ and also the results tended to be erroneous. In order to overcome this difficulty, carbon chip as bath were used. As Fig. 5 shows, the oxygen extraction was finished in about $300 \mathrm{~s}$. When samples more than $2 \mathrm{~g}$ were dropped into the crucible, the oxygen recovery tended to decrease slowly in sequence in the run. Therefore, carbon chip $(0.4 \mathrm{~g})$ were dropped into the crucible before the next sample was added in the crucible.

\section{Analytical results}

The analytical results obtained for the determination of oxygen in zinc, bismuth, lead and antimony are shown in Table 2 . The relative standard deviation for zinc by the carbon chiptin-nickel foil method were $14 \%$ at the level of 
Table 2 Analytical results of oxygen in zinc, bismuth, lead and antimony by carbon chip-tin-nickel foil bath method.

\begin{tabular}{|c|c|c|c|c|c|}
\hline \multirow{3}{*}{$\begin{array}{l}\quad \text { Sample } \\
\begin{array}{l}\mathrm{Zn}-1 \\
\text { (Block) }\end{array}\end{array}$} & \multicolumn{3}{|c|}{ Oxygen found(\%) } & \multirow{2}{*}{$\frac{\bar{x}(\%)^{*}}{0.0008}$} & \multirow{2}{*}{$\frac{C \cdot V \cdot(\%)^{* *}}{14}$} \\
\hline & 0.0007 & 0.0006 & 0.0009 & & \\
\hline & 0.0008 & 0.0008 & 0.0009 & & \\
\hline $\mathrm{Zn}-2$ & 0.18 & 0.17 & 0.19 & 0.18 & 5.1 \\
\hline (Block) & 0.17 & 0.17 & & & \\
\hline $\mathrm{Zn}-3$ & 0.10 & 0.11 & 0.095 & 0.11 & 11.4 \\
\hline (Block) & 0.10 & 0.13 & 0.11 & & \\
\hline $\mathrm{Bi}-1$ & 0.041 & 0.042 & 0.047 & 0.043 & 6.9 \\
\hline (Powder) & 0.047 & 0.039 & 0.043 & & \\
\hline $\mathrm{Bi}-2$ & 0.0031 & 0.0028 & 0.0036 & 0.0034 & 13 \\
\hline (Block) & 0.0032 & 0.0041 & & & \\
\hline $\mathrm{Pb}$ & 0.0075 & 0.0070 & 0.0079 & 0.0075 & 6.4 \\
\hline (Block) & 0.0069 & 0.0081 & 0.0077 & & \\
\hline $\mathrm{Sb}-1$ & 0.22 & 0.21 & 0.20 & 0.21 & 7.4 \\
\hline (Powder) & 0.19 & 0.21 & 0.24 & & \\
\hline $\mathrm{Sb}-2$ & 0.0091 & 0.0094 & 0.0095 & 0.0093 & 6.5 \\
\hline (Block) & 0.0084 & 0.0102 & & & \\
\hline
\end{tabular}

*Mean values. $\quad * *$ Relative standard deviation.

Table 3 Determination of oxygen in copper by carbon chip method.

\begin{tabular}{|c|c|c|c|c|c|c|c|c|}
\hline \multirow{3}{*}{ Sample } & \multicolumn{4}{|c|}{ Carbon chip method } & \multicolumn{4}{|c|}{ Other method } \\
\hline & \multirow{2}{*}{\multicolumn{2}{|c|}{ Found(\%) }} & \multirow{2}{*}{$\bar{x}(\%)$} & \multirow{2}{*}{ C.V. $(\%)^{* *}$} & \multicolumn{2}{|c|}{ No bath } & \multicolumn{2}{|c|}{ Fe bath } \\
\hline & & & & & $\bar{x}(\%)^{*}$ & C.V. $(\%)^{* *}$ & $\bar{x}(\%)^{*}$ & C.V. $(\%)^{* *}$ \\
\hline \multirow[t]{3}{*}{$\mathrm{Cu}-1$} & $0.0001_{8}$ & $0.0001_{5}$ & $0.0001_{7}$ & 6.9 & $0.0001_{5}$ & 17.2 & $0.0001_{6}$ & 15.4 \\
\hline & $0.0001_{7}$ & $0.0001_{6}$ & $0.0001_{8}$ & & & & & \\
\hline & $0.0001_{7}$ & $0.0001_{8}$ & & & & & & \\
\hline \multirow[t]{3}{*}{$\mathrm{Cu}-2$} & 0.0011 & 0.0013 & 0.0012 & 6.3 & $0.0009_{0}$ & 19.2 & 0.0012 & 16.1 \\
\hline & 0.0012 & 0.0012 & & & & & & \\
\hline & 0.0011 & 0.0013 & & & & & & \\
\hline
\end{tabular}

*Mean values of 6 determinations. ** Relative standard deviation.

$0.0008 \%$ oxygen(Zn-1) and $5.1 \%$ at the level of $0.18 \%$ oxygen $(\mathrm{Zn}-2)$. The poor precision for $\mathrm{Zn}-1$ seems to be due to the influence of oxygen contained in nickel foil (oxygen: $30 \mathrm{ppm}$ ) used. For the bismuth sample, the oxygen values in the powder(Bi-1) and block(Bi-2) bismuth samples were $0.0043 \%$ and $0.0036 \%$, with $6.9 \%$ and $13 \%$ relative standard deviation, respectively. The poor precision for the Bi-1 sample is considered to be due to the inhomogenity of the sample, but it is not evident in this matter.

In the lead samples, only the block sample was examined. The oxygen value was $0.0075 \%$ with $6.4 \%$ relative standard deviation. The analytical results for the powder antimony (Sb-
1) and block antimony(Sb-2) samples were also shown in Table 2 . The oxygen values obtained for $\mathrm{Sb}-1$ and $\mathrm{Sb}-2$ were $0.21 \%$ with $7.4 \%$ relative standard deviation and $0.0093 \%$ with $6.5 \%$ relative standard deviation, respectively. The precision obtained for $\mathrm{Sb}-1$ was poorer than that obtained for $\mathrm{Sb}-2$, because the powder antimony was blown up to the graphite lid at the dropping temperature of $1023 \mathrm{~K}$.

Table 3 shows the analytical results obtained for copper by the carbon chip method. Oxygen contents for oxygen-free copper( $\mathrm{Cu}-1)$ and electrolytic copper(Cu-2) were $0.0001_{5} \%$ with $6.9 \%$ relative standard deviation and $0.0012 \%$ with $6.3 \%$ relative standard deviation, respec- 
tively. The results obtained by the proposed method were significantly in good agreement with those obtained by the dry crucible method and iron bath one. But the proposed method was better precision than the other methods.

\section{Recovery test}

To check the accuracy of the carbon chiptin-nickel foil bath method, samples to be analyzed were prepared with known oxygen contents. For this purpose, the sample containing a known content of oxygen was mixed with metal oxides, and the mixtures were wrapped with nickel foil and analyzed. If the metal samples are of powder form, they are mixed with metal oxides for $300 \mathrm{~s}$ with a Spex mixermill (No. 8000). The mixtures were then pressed, wrapped with nickel foil and analyzed.

Table 4 Recovery of oxygen in samples prepared by adding metal oxides.

\begin{tabular}{cccc}
\hline \hline $\begin{array}{l}\text { Original } \\
\text { sample with } \\
\text { addition of } \\
\text { metal oxide }\end{array}$ & $\begin{array}{c}\text { Weight } \\
\text { of metal } \\
\text { oxide } \\
\text { added(mg) }\end{array}$ & $\begin{array}{c}\text { Amount } \\
\text { of metal } \\
\text { oxide } \\
\text { found(mg) }\end{array}$ & Recovery(\%) \\
\hline $\mathrm{Zn}$ & 25 & 24 & 96 \\
& 24 & 24 & 100 \\
& 4.1 & 4.3 & 105 \\
$\mathrm{Bi}$ & 3.0 & 2.8 & 93 \\
& 35 & 34 & 97 \\
& 45 & 46 & 102 \\
$\mathrm{~Pb}$ & 7.0 & 7.2 & 103 \\
& 4.0 & 4.0 & 100 \\
& 72 & 65 & 90 \\
& 35 & 32 & 91 \\
& 45 & 46 & $102^{*}$ \\
$\mathrm{Sb}$ & 7.1 & 7.2 & $101^{*}$ \\
& 6.8 & 6.5 & $96^{*}$ \\
& 73 & 73 & 100 \\
& 17 & 22 & 129 \\
& 6.6 & 7.0 & 106 \\
\hline \hline
\end{tabular}

* Recovery of $\mathrm{PbO}$ in Sample mixed with graphite powder.
Table 4 shows the data of the oxygen recovery test obtained by the carbon chip-tinnickel foil bath method. As Table 4 shows, the recovery of oxygen for zinc, antimony and bismuth were $96-104 \%$. However, for lead the oxygen was not completely extracted. This low oxygen extraction was considered to be caused by blowing up of the powder lead oxide from the crucible. To overcome this difficulties, the lead oxide was mixed with carbon powder (about $0.0074 \mathrm{~mm}$ and about $20 \mathrm{mg}$ ), and the mixture was wrapped together with lead containing a known content of oxygen and analyzed. The results showed the recovery of 95$100 \%$.

\section{REFERENCES}

(1) H. Hartmann and G. Strohl: Z. Anal. Chem., 175 (1960), 84.

(2) H. Hartmann, W. Hofman and K. S. Schrepping: Z. Metallk, 43 (1952), 350.

(3) J. Maatsch: Metall, 7 (1953), 873

(4) G. Serrini and W. Leyedecker: European Atomic Energy Community, EUR-2072i, Ispra, Italy, 1966.

(5) W. A. Baker: Metallurgie, 40 (1949), 188.

(6) K. Barteld and W. Hofman: Z. Erzbergbau Metallhuttenw, 7 (1954), 229.

(7) E. S. Funston and S. A. Reed: Anal. Chem., 23 (1951), 190.

(8) M. Chiba: J. Japan Inst. Metals: 43 (1980), 947 (in Japanese).

(9) J. Hoste, D. De Soete and A. Speecke: Nucl. Sci. Abstr., 22 (1968), 1948.

(10) T. Kurike, K. Ohsawa, E. Taniguchi, H. Oribe and K. Imaeda: Bunseki Kagaku, 26 (1977), 392.

(11) K. Imaeda, H. Ohsawa and T. Kuriki: ibid., 23 (1974), 1208.

(12) C. B. Griffith and E. Rodari: Anal. Chem. Acta, 42 (1968), 133.

(13) N. Yoneda: J. Japan Inst. Metals, 21 (1957), 392 (in Japanese).

(14) M. Saito and E. Sudo: ibid., 39 (1975), 396.

(15) E. Sudo, M. Saito, M. Chiba and A. Hashimoto: Bunseki Kagaku, 17 (1968), 1369.

(16) Japan Brass Makers Association: The Method for industrial analysis of copper and copper alloys, Ikubundo press, Tokyo, (1982), p. 158-164.

(17) M. Saito and E. Sudo: Bunseki Kagaku, 24 (1975), 248. 